\title{
MODELOS DIDÁTICOS COMESTÍVEIS COMO UMA TÉCNICA DE ENSINO E APRENDIZAGEM DE BIOLOGIA CELULAR
}

\author{
Keiciane Canabarro Drehmer Marques*
}

\begin{abstract}
Resumo: O Ensino de Biologia apresenta inúmeros conteúdos com abstrações que dificultam os processos de aprendizagens dos estudantes, um destes é a Biologia Celular, por tratar de estruturas microscópicas gera certo distanciamento aos educandos. Neste contexto, observouse a importância de utilizar recursos didáticos que podem auxiliar na aprendizagem e permitir o protagonismo dos discentes. A atividade realizada constituiu-se na construção de modelos de células comestíveis por cinco turmas de $1^{\circ}$ ano do Curso Técnico em Agropecuária Integrado ao Ensino Médio do Instituto Federal Farroupilha - Campus São Vicente do Sul/RS. O processo de planejamento até a montagem das células comestíveis envolveu os estudantes de maneira intensa, os mesmos participaram ativamente, com interesse e motivação. A confecção dos modelos comestíveis propiciou a construção do próprio conhecimento em um conteúdo abstrato, materializando este para ajudar na compreensão. A atividade possibilitou o desenvolvimento de diversas competências nos estudantes que vão além dos conteúdos conceituais da Biologia, permitindo a formação integral do educando em todas as suas dimensões.
\end{abstract}

Palavras-chave: Modelos didáticos. Biologia Celular. Ensino de Biologia

\section{Introdução}

O Ensino de Ciências é marcado por inúmeras abstrações e memorização de nomenclaturas, esses são alguns dos motivos que repelem parte dos estudantes de gostar de disciplinas como Biologia. Diante desta problemática, é necessário investir em alternativas didáticas que visem a atrair os discentes e a facilitar os processos de aprendizagem perante os conteúdos abstratos. Krasilchik (2004) destaca que o Ensino Médio é abordado ainda de forma descritiva, sem vinculação, com inúmeras terminologias, ou seja, um ensino enciclopédico.

É necessário modificar este ensino enciclopédico e utilizar diferentes recursos didáticos no Ensino de Ciências propiciando uma melhora no processo de aprendizagem dos educandos, principalmente relacionado com conteúdo de compreensão mais dificultosa. Uma das possibilidades para auxiliar no processo de aprendizagem é a utilização de modelos didáticos para o Ensino de Biologia, na tentativa de representar estruturas microscópicas. A pesquisadora Krasilchik (2004) enfatiza que os modelos didáticos são um dos recursos didáticos mais utilizados nas aulas de Biologia. Em relação aos modelos didáticos utilizados para o Ensino de Ciências, os autores Justina e Ferla (2006) afirmam

\footnotetext{
* ${ }^{1}$ Doutoranda em Educação em Ciências da Universidade Federal de Santa Maria- RS. E-mail: keicibio@gmail.com
} 
[...] a utilização de modelos didáticos para o ensino de biologia, pois a visualização de uma estrutura em três dimensões, podendo facilitar o processo de ensino e aprendizagem nos diferentes níveis de ensino. Os modelos didáticos são representações, confeccionadas a partir de material concreto, de estruturas ou partes de processos biológicos (JUSTINA; FERLA, 2006, p.35)

A aplicação de modelos didáticos em conteúdo de maior abstração é de grande valia para representar aos estudantes de modo concreto estruturas não visíveis. O conteúdo de Biologia Celular mesmo sendo abordado em diversos anos escolares, iniciando-se a partir do Ensino Fundamental, por ser de difícil visualização, necessita de recursos adicionais para que a aprendizagem ocorra (SILVA et al. 2014). Dentre os diversos assuntos da Biologia, Petrovich e colaboradores (2014) realizaram uma pesquisa para evidenciar os conteúdos que geram maior dificuldade na aprendizagem dos estudantes e os assuntos relacionados à Biologia Celular ficaram em primeiro lugar da lista. Os pesquisadores supracitados acima afirmam que os conteúdos relacionados à célula, mesmo que abordado nos diferentes níveis de ensino, sua complexidade, fragmentação e abstração tornam este conteúdo da disciplina de Biologia o que os educandos apresentam maior dificuldade. Necessita-se, assim, investir em recursos didáticos que facilitem a compreensão em conteúdos não palpáveis e que gerem interesse na aprendizagem por parte dos estudantes.

Neste trabalho, tem-se como objetivo representar modelos didáticos comestíveis para auxiliar no estudo de Biologia Celular, por esse ser um conteúdo abstrato aos educandos e com estruturas microscópicas. Almeja-se assim auxiliar na aprendizagem da Biologia de forma atrativa e também desenvolver diferentes competências aos estudantes na busca por uma formação integral, ou seja, em todas as dimensões.

\section{Percursos metodológicos}

O trabalho ocorreu no primeiro semestre do ano de 2017 com cinco turmas do $1^{\circ}$ ano do Curso Técnico em Agropecuária Integrado ao Ensino Médio do Instituto Federal Farroupilha- Campus de São Vicente do Sul/ Rio Grande do Sul. A atividade desenvolvida foi a construção de modelos de células comestíveis e constituiu-se em cinco etapas (Quadro $1)$. 
Quadro 1- Etapas da elaboração da atividade de células comestíveis.

\begin{tabular}{|l|l|}
\hline Etapas & Tempo destinado \\
\hline $1^{\circ}$ Lançamento da proposta & 25 minutos \\
\hline $2^{\circ}$ Organização dos grupos e modelo sorteado & 50 minutos \\
\hline $3^{\circ}$ Pesquisa e planejamento & 1 mês \\
\hline $4^{\circ}$ Montagem e organização & 70 minutos \\
\hline $5^{\circ}$ Apresentação & 40 minutos \\
\hline
\end{tabular}

Fonte: Elaborado pela autora

A primeira etapa do trabalho de construção de células comestíveis consistiu no lançamento da proposta para as turmas, este momento foi explanado pela professora regente da disciplina de Biologia, a proposta apresentada foi a construção de células comestíveis, sendo essa uma das atividades avaliativas do semestre. A ideia de lançar a proposta aos educandos e verificar a opinião destes sobre a possibilidade do trabalho foi devido à realidade das turmas em que grande parte dos estudantes moram em outras cidades, alguns utilizam a moradia estudantil do IFFar ou pensões próximas, e a atividade em questão poderia ser inviável ou difícil de ser executada e até mesmo gerar gastos dispendiosos. Esta etapa de explicar a tarefa ocorreu nas cinco turmas e todas aceitaram a realização do trabalho afirmando que seria interessante, possível e não geraria gastos desnecessários. Desta forma, as cinco turmas realizaram a atividade, cada turma em seus períodos de Biologia.

$\mathrm{Na}$ segunda etapa, ocorreu a organização dos grupos e sorteio do modelo a ser construído. A forma de organização dos grupos diferiu, pois algumas turmas optaram por fazer o grupo de acordo com afinidades e outras pediram a realização de um sorteio ao acaso para formar os grupos. O número de integrantes variou de quatro a seis estudantes, após a organização dos grupos realizou-se o sorteio com os possíveis modelos de células a serem construídas:

a) Modelo de célula procarionte

b) Modelo de célula eucarionte vegetal

c) Modelo de célula animal: a, b e c

d) Modelo da partícula viral 
Nos modelos de célula eucarionte animal foram elaborados três tipos de células entre elas: óvulo, espermatozoide e neurônio. A inserção do modelo de partícula viral, mesmo sendo acelular, foi com o intuito de representar suas estruturas e composição abordando diferenças e semelhança com os modelos de célula.

Posterior a organização dos grupos e a realização do sorteio do modelo comestível a ser construído, os estudantes tiveram aproximadamente um mês para realizar a pesquisa sobre a célula sorteada, como sua estrutura, tamanho, formato, organelas, funções e demais características. Neste tempo deveriam realizar o planejamento de como seria elaborado o modelo comestível, os alimentos que seriam utilizados, de que forma seria a montagem e entre outros detalhes a serem discutidos. No período de aproximadamente um mês a professora de Biologia e autora deste artigo disponibilizou horários no turno inverso às aulas para atender os grupos e auxiliar nas pesquisas e planejamento dos que necessitassem.

A quarta e quinta etapa ocorreram no mesmo dia na sequência, para etapa de montagem e apresentação dos modelos comestíveis utilizou-se o laboratório de aulas práticas do curso de Tecnologia de Alimentos, o qual apresenta toda estrutura de uma grande cozinha com talheres, mesas, louças, panelas, forno, fogão, eletrodomésticos como batedeira, microondas, liquidificador entre outros. Cabe salientar que foram realizados os devidos cuidados em relação à limpeza e higiene, utilizando álcool gel para limpeza das mãos, álcool para limpeza das mesas, além do uso de toucas e aventais descartáveis para todos os estudantes.

Na etapa da montagem e organização do espaço, as turmas diferiram quanto ao tempo que precisaram variando de 45 a 70 minutos, alguns grupos levaram a base do modelo comestível pronto e outros cozinharam na hora. Na quarta etapa, os grupos deveriam montar a célula comestível com os alimentos previamente selecionados e posteriormente organizar o espaço utilizado. Nesta etapa os estudantes deveriam identificar seu modelo de célula comestível e suas partes com plaquinhas de palito e papel.

A última etapa consistiu na apresentação do modelo comestível para turma, suas caraterísticas, organelas e demais curiosidades que julgassem pertinente.

\section{Resultados e discussões}

O trabalho realizado com as cinco turmas de $1^{\circ}$ ano do Curso Técnico em Agropecuária Integrado ao Ensino Médio possibilitou abordar diversas competências com os educandos como: planejar, pesquisar, organizar, montar, explicar, indicar, diferenciar, criar, localizar, construir entre outras competências abordadas ao longo da atividade. Os 
documentos oficiais como os Parâmetros Curriculares Nacionais do Ensino Médio (PCNEM) destacam a construção de competências:

O Ensino Médio, portanto, é a etapa final de uma educação de caráter geral, afinada com a contemporaneidade, com a construção de competências básicas, que situem o educando como sujeito produtor de conhecimento e participante do mundo do trabalho, e com o desenvolvimento da pessoa, como "sujeito em situação" - cidadão (PCNEM, 2000, p.10).

O desenvolvimento de competências é uma das atribuições da educação para o mundo do trabalho, mas sobretudo para o desenvolvimento do sujeito aprendente para qualquer situação que surja, comprometendo-se com a formação integral do educando como sujeito crítico e reflexivo nas diversas situações e não apenas como adestramento para executar competências no mundo do trabalho.

A atividade de construção de modelos comestíveis contou com a participação de aproximadamente 150 estudantes, cada turma com cerca de 30 estudantes realizou a construção de modelos celulares comestíveis ao longo dos períodos de Biologia. A construção foi realizada pelos grupos anteriormente definidos e estes realizaram a montagem das células em aula, elaborando a base e acrescentando coberturas e demais alimentos para representarem as organelas e estruturas presentes (Figura 1). As figuras apresentadas neste trabalho têm a permissão do Instituto Federal Farroupilha bem como dos estudantes que permitem no ato da matrícula autorização da imagem, tratando-se de atividades institucionais de ensino/pesquisa.

Figura 1- Construção das modelos comestíveis pelos estudantes do $1^{\circ}$ ano dos cursos integrados em Agropecuária.

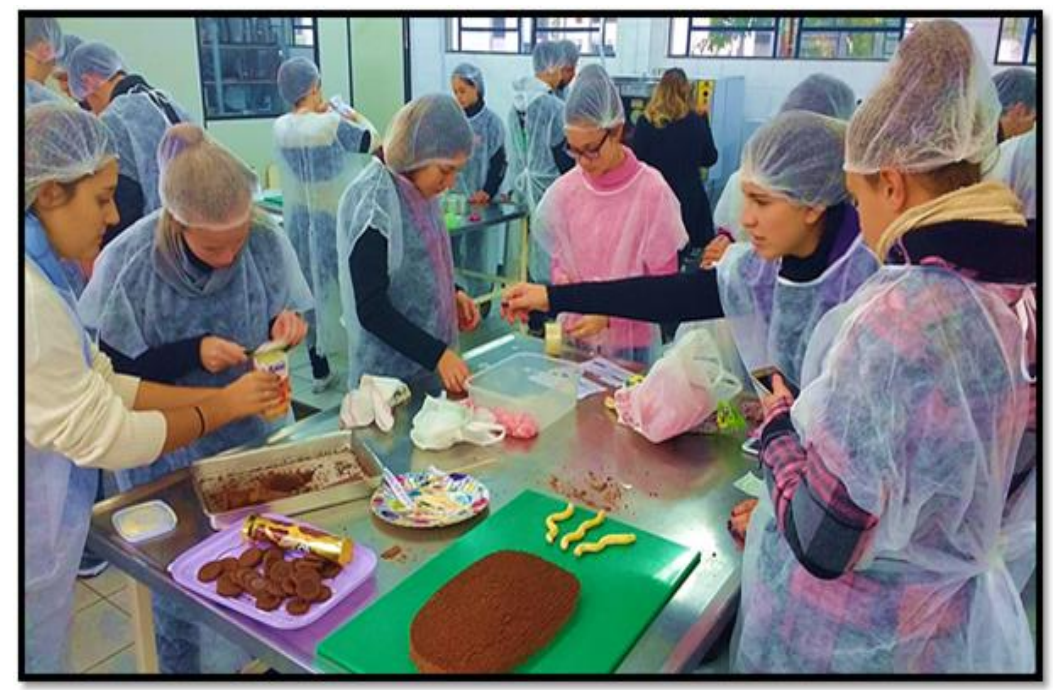

Fonte: Autora 
Os estudantes envolveram-se na construção dos modelos didáticos comestíveis, a participação ativa dos grupos assemelha-se aos resultados obtidos por Silva et al. (2014) em que os estudantes ficaram envolvidos na construção de modelos didáticos de células. Os educandos deste estudo demostraram motivação e intensa participação na construção de modelos de Biologia Celular comestíveis, semelhantemente aos participantes do estudo realizado por Orlando et. al (2009).

Os grupos receberam uma folha impressa (Figura 2) com a identificação dos tipos de células e organelas/estruturas presentes, porém todos os grupos receberam a mesma folha e tinham a tarefa de identificar as suas plaquinhas recortando-as e colocando em palitos de madeira, para posteriormente identificar no modelo comestível.

Figura 2- Folha com tipos de células e organelas/estruturas.

\begin{tabular}{|c|c|c|c|c|}
\hline \multicolumn{4}{|c|}{ CÉLULA ANIMAL } & ÍRUS \\
\hline \multicolumn{4}{|c|}{ CÉLULA VEGETAL } & VULO \\
\hline \multicolumn{4}{|c|}{ ESPERMATOZOIDE } & Centríolo \\
\hline \multirow{2}{*}{\multicolumn{4}{|c|}{ CÉLULA BACTERIANA }} & DNA \\
\hline & & & & RNA \\
\hline \multicolumn{3}{|c|}{ NEURÔNIO } & Mitocôndria & Núcleo \\
\hline Pescoço & Cabe & \multicolumn{2}{|c|}{ Lisossomo } & Peroxissomo \\
\hline \multicolumn{3}{|c|}{ Membrana plasmática } & Cápsula & Proteínas \\
\hline \multicolumn{2}{|c|}{\begin{tabular}{|l||l} 
Ribossomo & $\mathrm{Fl}$ \\
\end{tabular}} & Flagelo & Carioteca & Plasmídec \\
\hline \multicolumn{2}{|c|}{ Corpo celular } & \multicolumn{2}{|c|}{ Parede celular } & Axônio \\
\hline \multicolumn{2}{|c|}{ Corona radiata } & \multicolumn{2}{|c|}{\begin{tabular}{|l|} 
Envelope \\
\end{tabular}} & Dendritos \\
\hline \multicolumn{2}{|c|}{ Citoplasma } & \multicolumn{2}{|c|}{ Cloroplasto } & Capsídeo \\
\hline \multicolumn{2}{|c|}{ Acrossoma } & \multicolumn{2}{|c|}{ Zona pelúcida } & Vacúolo \\
\hline \multicolumn{4}{|c|}{ Retículo endoplasmático } & Pelos ou Pili \\
\hline \multicolumn{3}{|c|}{ Complexo de Golgi } & Bainha de & mielina \\
\hline
\end{tabular}

Fonte: Material construído pela autora

Durante esta etapa, os grupos deveriam colocar em prática parte os conhecimentos obtidos por meio da pesquisa e estudos realizados sobre o modelo que haviam sorteado, recortando as plaquinhas que pertenciam apenas ao seu modelo. Um trabalho semelhante o 
qual envolveu a confecção de modelos de células, porém com a utilização de material permanente, realizado por Kierepka, Güllich e Hermel (2015), destaca que além de proporcionar que os estudantes ajam como autores do processo de construção do conhecimento, a materialização da parte interna das células possibilita uma compreensão mais detalhada e de substancial importância em conteúdos abstratos como de Biologia Celular. Vale destacar que células são visíveis ao microscópio óptico, porém algumas de suas organelas não, ficando retratadas apenas imagens utilizadas nos livros didáticos. Após a construção dos modelos comestíveis, os educandos realizaram a limpeza e organização do ambiente e na sequência realizaram a apresentação dos trabalhos produzidos (Figura 3).

Figura 3- Alguns dos modelos comestíveis construídas pelos educandos.

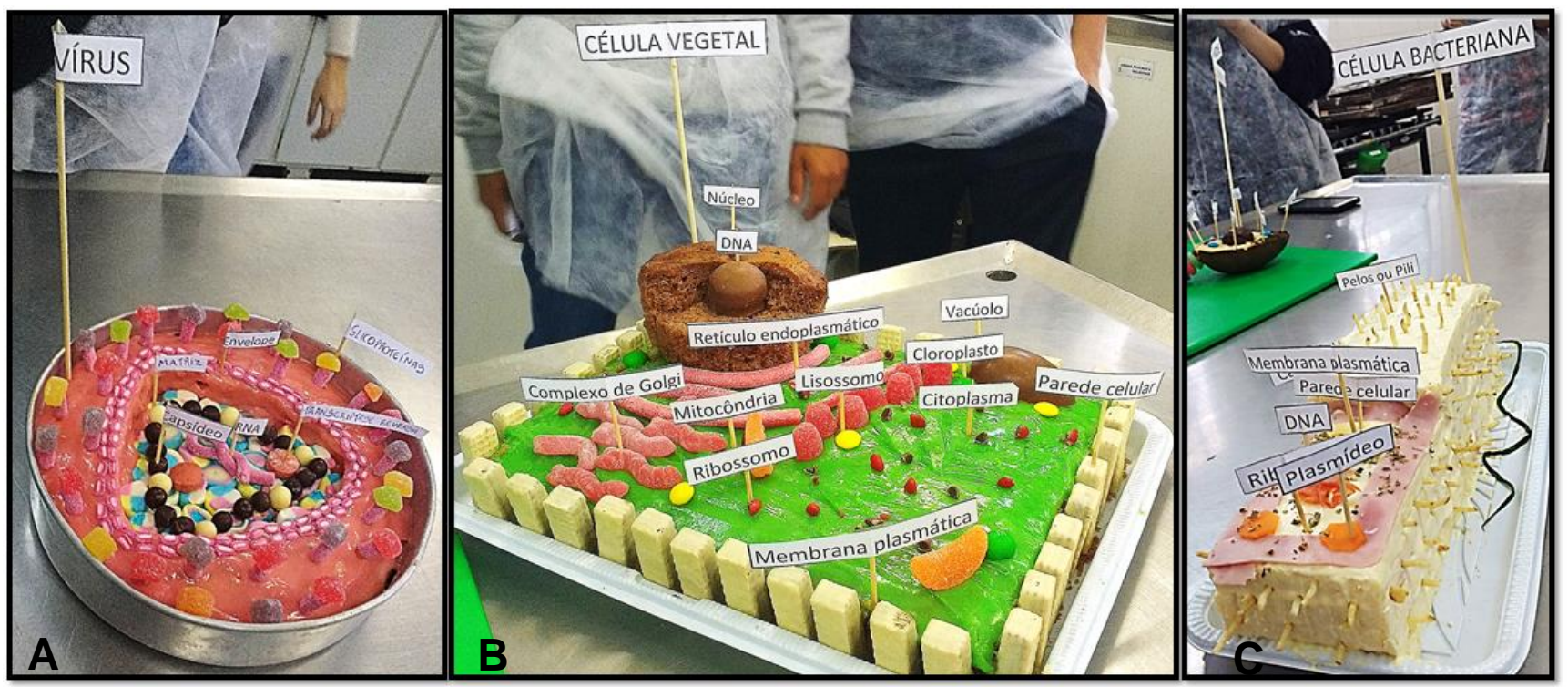

Legenda: A) Modelo da partícula viral de um vírus do HIV; B) Modelo da célula do tipo eucarionte vegetal;

C) Modelo da célula do tipo procarionte;

Fonte: Autora

Cada grupo apresentava sua célula comestível ao restante da turma explicando sua função, formato, organelas presentes ou não, e demais características pesquisadas. Ao finalizar apresentação a professora de Biologia realizava alguns questionamentos ao grupo acerca do trabalho e do modelo construído relacionando com o conteúdo de Biologia Celular. Os questionamentos eram lançados com base na apresentação dos grupos para verificar se os estudantes entenderam o modelo elaborado ou apenas memorizaram as informações para apresentação, alguns dos questionamentos lançados "O que a partícula viral apresenta em comum com uma célula?", "Todas as bactérias apresentam plasmídeo? E qual a função desse?”, “O que uma célula procarionte apresenta em comum e de diferenças com uma célula 
eucarionte?", "Por que a célula vegetal está representada sua maior parte da cor verde?", "Por que todas as mitocôndrias do espermatozoide fica na peça intermediária?”, "Por que o óvulo apresenta a chamada corona radiata e zona pelúcida e as outras células não?”, “O que difere uma célula eucarionte animal de uma eucarionte vegetal"?, "Por que o neurônio, espermatozoide e óvulo são classificados como eucarionte animal e não eucarionte vegetal?", "Por que a célula vegetal construída está com parede celular e animal não?", "Por que não foi apresentado vacúolo de suco celular nas células animais?", "Os vírus são classificados procariontes ou eucariontes?" entre outras perguntas que foram abordadas. Os questionamentos tinham objetivo de provocar a reflexão e o debate para que os estudantes elaborassem suas explicações com base nas pesquisas realizadas. Até mesmo percebessem que algumas perguntas eram para testá-los como o exemplo do vírus ser procarionte ou eucarionte, uma vez que esse não é constituído por célula e não apresenta esta classificação.

Os estudantes foram avaliados durante todas as etapas do trabalho, desde a organização, pesquisa e planejamento, limpeza, apresentação, interação entre o grupo e a identificação das placas inseridas nas estruturas das células. A avaliação ocorreu de forma contínua e cumulativa, prevalecendo os aspectos qualitativos, conforme indicação do PPC do Curso Técnico em Agropecuária Integrado ao Ensino Médio do campus São Vicente do Sul (IFFar, 2014, p.28) "Para avaliação do rendimento dos estudantes, serão utilizados instrumentos de natureza variada e em número amplo o suficiente para poder avaliar o desenvolvimento de capacidade e saberes, com ênfases distintas".

A atividade realizada na construção de células comestíveis atingiu o objetivo proposto de modo a facilitar o processo de ensino e aprendizagem da Biologia Celular de modo lúdico e atrativo, uma vez que este é um conteúdo “impalpável” e trata-se de estruturas microscópicas, o que dificulta o entendimento dos educandos. Kierepka, Güllich e Hermel (2015) destacam que o conteúdo abstrato como o de Biologia Celular pode ter facilitada sua compreensão por meio de alternativas pedagógicas como desenvolvimento de modelos didáticos. O trabalho realizado por Orlando et al. (2009) aponta que a confecção de modelos didáticos ajudou no entendimento das células e das estruturas relacionadas a essas, desta forma observamos que os resultados obtidos por Orlando e seus colaboradores (2009) vão ao encontro dos alcançados neste trabalho, em que houve melhora na aprendizagem dos discentes após a construção dos modelos didáticos.

Desta forma a construção de modelos comestíveis torna o ensino de Biologia Celular mais visível e interessante aos estudantes, fato este que pode ser comprovado com depoimentos dos discentes ao longo da apresentação dos trabalhos que afirmaram ser um 
modo divertido e descontraído de estudar Biologia. Houve uma melhoria nas notas das avaliações do tipo prova após a realização da atividade de modelos comestíveis comparada a avaliação anterior a esta abordagem, ambas as avaliações referentes aos conteúdos de Biologia Celular. Nesse contexto, a inserção da atividade didática pode ter auxiliado na compreensão dos discentes, as avaliações quantitativas não serão abordadas com ênfase neste trabalho, pois não é o objetivo da proposta. A realização da atividade possibilitou que a professora reconhecesse limitações e erros conceituais ainda presentes no conteúdo de Biologia Celular, através da apresentação oral, assim como pelas plaquinhas inseridas nas células em locais incorretos ou até mesmo estruturas que não eram condizentes com o tipo de célula do grupo em questão. Assim, sendo possível questionar e orientar o grupo no momento da apresentação, auxiliando nessas limitações. Kierepka, Güllich e Hermel (2015) destacam que o ensino não deve priorizar as memorizações e sim permitir a atuação ativa dos estudantes na construção dos seus conhecimentos por meio da confecção autônoma dos modelos de células.

\begin{abstract}
Muitos alunos encontram dificuldade em aprender conceitos abstratos como aqueles que são ensinados em citologia, pois nos livros didáticos existem apenas explicações do conceito com desenhos ilustrativos. Assim, a abordagem dos conteúdos de citologia no ensino de ciências, normalmente apresenta uma gama de conceitos e fundamentos abstratos e distantes do universo cotidiano do discente. Dessa forma, o uso de instrumentos didático-pedagógicos pode contribuir positivamente no processo de aprendizagem (SILVA et al., 2014, p.65).
\end{abstract}

A utilização de modelos comestíveis pode auxiliar na compreensão dos conteúdos relacionados à Biologia Celular em relação às diferenças e às semelhanças entre os modelos construídos. Já que é de grande valia que os estudantes saibam diferenciar os tipos de células e da partícula viral e entendam suas especificidades, onde são encontradas e como funcionam. A elaboração dos modelos possibilita uma compreensão geral sobre a Biologia Celular, esta parte do conteúdo também é marcada por inúmeras terminologias, Motokane (2015) argumenta que a Biologia abordada nas escolas é carregada de nomenclaturas e descrições. O pesquisador destaca também que discentes e docentes reconhecem a importância das terminologias e conceitos para organização das aulas, porém o Ensino de Biologia não pode ser visto apenas como uma lista de nomenclaturas intermináveis, há muito mais desta disciplina a ser abordado.

Vale a reflexão: o que interessa mais aos docentes de Biologia que seus alunos saibam uma lista de termos sem saber ao certo sua importância e conceituação, ou compreender fenômenos, processos e diferenças entre os seres vivos? O autor supracitado aponta que não há necessidade em memorizar todas as terminologias uma vez que os estudantes podem 
consultar a definição ou contar com auxílio do docente quando necessitarem. É uma constante busca pelo equilíbrio, pois apresentar as terminologias se faz necessário ao Ensino de Biologia, mas a compreensão dos processos e as diferenças entre os seres destacam-se como de grande importância ao processo de ensino e aprendizagem. Desta forma, os modelos comestíveis não superam completamente a memorização, mas auxiliam na compreensão geral dos tipos de células e vírus de modo mais atrativo que uma aula somente expositiva. Isso, pois o estudante tem a possibilidade de usar a criatividade aliada à descontração para criar um modelo comestível, de modo a gerar aprendizagem sobre características e diferenças entre as células.

A falta de visualização e contextualização do conteúdo de células distancia da realidade dos discentes ficando a imagem dos livros de forma abstrata. Diante do exposto, a elaboração dos modelos comestíveis apresenta inúmeros aspectos positivos como a questão de atividades práticas, estímulo à aprendizagem de Biologia Celular que se trata de assuntos mais abstratos, cooperação e organização entre os estudantes entre outros. Convém destacar que entre os aspectos negativos está a dedicação de tempo maior destinado ao conteúdo de células, maior envolvimento e requer investimentos financeiros. Silva et al. (2014) realizaram a construção de modelos de células com os estudantes e destacaram os gastos como aspecto negativo do trabalho, porém a atividade desenvolvida por Silva e seus colaboradores (2014) foi a maquete, que foi construída com material permanente como papel EVA, tinta, biscuit entre outros.

A escolha pela construção de modelos comestíveis justifica-se pelo fato que inúmeros modelos de células são construídas anualmente na disciplina de Biologia, porém essas utilizam de materiais como isopor, tinta, papel EVA, gerando custos e principalmente acúmulo de resíduos, uma vez que após a construção das maquetes acabam sendo descartadas no lixo. A possibilidade de construção de modelos utilizando alimentos tornou o trabalho totalmente aproveitável após a montagem, pois as células foram degustadas em sua totalidade pelas turmas que as elaboraram, tornando-se uma atividade com ênfase no Ensino de Biologia de forma atrativa e saborosa aos estudantes com consciência ambiental, sem gerar acúmulo de lixos.

A elaboração de modelos didáticos comestíveis mostrou-se como um recurso didático com potencial de atratividade aos educandos, por meio do entusiasmo gerado os estudantes os quais pesquisaram e construíram suas células de modo prazeroso permitindo a inserção de terminologias da Biologia de forma diferenciada e dinâmica. Auxiliou assim no aprendizado de Biologia Celular, que costuma ser de difícil compreensão e abstrato as discentes. 


\title{
4 Considerações finais
}

O trabalho de modelos comestíveis, além de contribuir ao processo de aprendizagem de Biologia Celular, proporcionou o desenvolvimento de inúmeras competências aos educandos como capacidade de: organização, pesquisa, planejamento, integração, cooperativismo, oralidade entre outras. Com a perspectiva de construção de modelos didáticos comestíveis, possibilitou-se um Ensino de Biologia mais atrativo e dinâmico, de modo a minimizar as memorizações desconexas e valorizar a construção do conhecimento acerca da Biologia Celular em relação às diferenças entre os tipos de células e da partícula viral. Ainda, propiciou a abordagem de conceitos abstratos de modo concreto por meio da elaboração do modelo com alimentos.

A experiência de elaborar modelos comestíveis foi de grande proveito para os educandos que participaram ativamente da construção de suas células tornando conceitos de difícil compreensão da Biologia Celular como um facilitador por meio dos modelos comestíveis. Atividades práticas e diferenciadas que possibilitem o protagonismo discente devem ser incentivadas pelos docentes de Biologia, permitindo o Ensino de Ciências mais atrativo e prazeroso aos educandos.

Pode-se destacar que a utilização dos modelos didáticos concretos para auxiliar em conteúdos mais abstratos permite um maior interesse pelo assunto e possibilita melhora na aprendizagem. Isso foi observado ao longo da execução da atividade em que os estudantes iam debatendo com os grupos como era o modelo em construção de modo a retomar as características gerais pesquisadas e estudadas. O modelo didático possivelmente auxiliou na melhora do aprendizado comparando as duas avaliações realizadas sobre Biologia Celular, uma antes da atividade do modelo comestível e outra posterior com um aumento nas notas e na média das turmas. Atividades lúdicas possibilitam apresentar a Biologia de forma atrativa e interessante, possibilitando uma maior interação entre os educandos com a disciplina em questão.

\section{EDIBLE DIDACTIC MODELS AS A TECHNIQUE OF TEACHING AND LEARNING ABOUT CELLULAR BIOLOGY}

\begin{abstract}
The Teaching of Biology presents so many contents with abstractions that make difficult the learning processes of the students, one of these is the Cell Biology, because dealing with microscopic structures generate a certain distance from the students. In this context, it was observed the importance of using didactic resources that can aid in the learning and allow the protagonism of the students. The activity was constituted in the construction of
\end{abstract}


models of edible cells by five classes of 1st year of the Technical Course in Agropecuarian Integrated to High School of Instituto Federal Farroupilha - Campus São Vicente do Sul/RS. The planning process until the assembly of the edible cells involved the students intensely, they participated actively, with interest and motivation. The making of the edible models allowed the construction of the own knowledge in an abstract content, materializing this one to aid in the understanding. The activity made possible the development of several competences in the students that go beyond the conceptual contents of Biology, allowing the integral formation of the student in all its dimensions.

Keywords: Didactic models. Cell biology. Teaching of Biology.

\section{Referências}

BRASIL. Ministério da Educação. Secretaria de Educação Média e Tecnológica. Parâmetros Curriculares Nacionais do Ensino Médio (PCNEM). Brasília: MEC, 2000.

IFFAR, Instituto Federal Farroupilha, campus São Vicente do Sul. Projeto Pedagógico do Curso Técnico em Agropecuária Integrado. Resolução CONSUP n ${ }^{\circ} 125$, de 28 de novembro de 2014. Disponível em:

<http://w2.iffarroupilha.edu.br/site/midias/arquivos/201511219148494tecnico_em_agropecua ria_integrado.pdf $>$. Acesso em: 19 jul. 2018.

JUSTINA, L. A. D.; FERLA, M. R. A. A utilização de modelos didáticos no ensino de genética - exemplo de representação de compactação do DNA eucarioto. Arquivos do Museu Dinâmico, Maringá, v.10, n. 2, p. 35-40, 2006.

KIEREPKA, J. S. N.; GÜLLICH, R. I. C., HERMEL, E. E. S. O ensino da biologia celular por meio da confecção de modelos didáticos. In: III Congresso Internacional de Educação Científica e Tecnologia, 2015.

KRASILCHIK, M. Práticas do ensino de biologia. São Paulo: EDUSP, 2004, 200p.

MOTOKANE, M. T. Sequências Didáticas Investigativas e argumentação no ensino de ecologia. Revista Ensaio, Belo Horizonte, v.17, nov., 2015, p.115-137.

ORLANDO, T. C. et al. Planejamento, montagem e aplicação de modelos didáticos para abordagem de Biologia Celular e Molecular no Ensino Médio por graduandos de Ciências Biológicas. Revista de Ensino de Bioquímica, v. 7, n. 1, p. 1-17, 2009.

PETROVICH, A.C. et al. Temas de difícil ensino e aprendizagem em ciências e biologia: experiências de professores em formação durante o período de regência. Revista de Ensino de Biologia da Associação Brasileira de Ensino de Biologia (SBEnBio), Niterói, v.7, p.363-373, 2014.

SILVA, E. et al. O uso de modelos didáticos como instrumento pedagógico de aprendizagem em citologia. Revista de ciências exatas e tecnologia, Londrina, v. 9, n. 9, p. 65-75, 2014. 